\title{
RISK FACTORS FOR SELF-REPORTED CARPAL TUNNEL SYNDROME AMONG HAIRSTYLISTS IN GABORONE, BOTSWANA
}

\author{
PATIENCE ERICK, KELETSO BENJAMIN, SAMUEL RADITLOKO, ROY TAPERA, and BONTLE MBONGWE
}

University of Botswana, Gaborone, Botswana

Faculty of Health Sciences, Department of Environmental Health

\begin{abstract}
Objectives: Hairstylists form an occupational group whose tasks involve repetitive and forced movements of hands and wrists, thus posing a risk of developing carpal tunnel syndrome (CTS). This study assessed the prevalence of and factors associated with CTS symptoms among hairstylists in Gaborone, Botswana. Material and Methods: A cross-sectional study was conducted using a self-administered questionnaire distributed among randomly selected hairstylists. The questionnaire gathered information on demographic characteristics, lifestyle, work-related characteristics and psychosocial factors. The Boston Carpal Tunnel Syndrome Questionnaire was used to determine the severity of CTS symptoms and its functional effects. Data were then analyzed using $\chi^{2}$ and logistic regression models. The level of significance was determined at $p<0.05$. Results: A total of 165 hairstylists took part in the study, with $92(56 \%)$ of the respondents being females. The mean age $(\mathrm{M} \pm \mathrm{SD})$ of the respondents was $35.05 \pm 7.54$ years with an age range of 22-63 years. Seventy-three (42.2\%) hairstylists reported CTS symptoms, with the majority (73\%) being females. Out of all the CTS cases, $53(72.6 \%)$ and $16(21.9 \%)$ had mild and moderate symptoms, respectively. Over $80 \%$ of the hairstylists did not know about CTS. Among individual factors, CTS symptoms were associated with being female (the odds ratio [OR] of 9.99, and the $95 \%$ confidence interval [CI]: 3.64-27.44), increasing age (OR 9.84, 95\% CI: 2.74-35.36), the length of employment (OR 3.73, 95\% CI: 1.39-9.95), hair washing (OR 2.88, 95\% CI: 1.41-5.85), an awkward posture (OR 2.52, 95\% CI: 1.03-6.19), and the use of a great muscular effort when performing a task (OR 2.39, 95\% CI: 1.01-5.72). Perceived heavy workload and stressful work were also risk factors. Conclusions: The results suggest a high prevalence of CTS among female hairstylists in Gaborone, and also point out that individual, work-related and psychosocial factors are associated with this syndrome. Future large-scale research is needed to establish the extent of CTS countrywide to influence policy-making. Currently, CTS is not listed amongst occupational health diseases in Botswana. Int J Occup Med Environ Health. 2021;34(3):437-50
\end{abstract}

Key words:

carpal tunnel syndrome, barbers, hairdressers, hand/wrist pain, hairstylists, upper-limb pain

\section{INTRODUCTION}

Carpal tunnel syndrome (CTS) is a leading cause of upper-limb musculoskeletal disorders, which are among the most significant and costly health problems occurring in the working population worldwide. It is described as an entrapment neuropathy that occurs as a result of compression of the median nerves due to increased pressure in the carpal tunnel [1]. Generally, CTS development has been linked to various systematic diseases such as diabetes mellitus, thyroid dysfunction, rheumatoid arthritis, pregnancy, obesity, and osteoarthritis, as well as to repetitive wrist movements [2]. Although not uniquely caused by work, CTS represents a major proportion of all registered or compensable work-related diseases in many countries [3]. It is further associated with significant worker compensation costs, lost time, lost productivity and impaired fitness to work [4]. Pre-

Received: May 14, 2020. Accepted: November 2, 2020.

Corresponding author: Patience Erick, University of Botswana, Faculty of Health Sciences, Department of Environmental Health, 4775 Notwane Road, Gaborone, Botswana (e-mail: erickp@ub.ac.bw). 
vious epidemiological studies have identified some associations of CTS with individual and psychosocial factors, such as repetitive/prolonged hand-intensive activities, forceful exertions of the hand, awkward and/or static postures, extreme temperatures, and localized mechanical stress [3,5]. Hairdressers are among the occupational groups whose working ability and health conditions may be prone to CTS. A job task of a hairdresser includes braiding, washing and drying the hair and, in some instances, dreadlock planting, twisting and styling. These activities involve forced or repetitive hand movements. Furthermore, hairdressing involves the use of some devices such as scissors and vibrating tools, and techniques which are likely to aggravate CTS, tendinitis and epicondylitis [6]. A high prevalence of CTS has been reported among hairdressers compared to the rest of society due to the use of scissors and other tools for prolonged periods [6].

The daily workload of hairdressers has been reported to be high and aggravated by the lack of regular breaks. A study carried out in France found that in 2002-2004 $86.6 \%$ of new CTS cases among female hairdressers were associated with work-related factors. Hence, hairdressing was in the top 10 high-risk occupations for CTS [7].

Despite their large demographic and associated potential for occupational health problems, few epidemiological studies have investigated the CTS prevalence and risk factors among hairdressers, especially in developing countries. The aim of this study was, therefore, to determine the prevalence and severity of self-reported CTS among hairstylists in Gaborone, Botswana, and to establish the risk factors associated with its development.

\section{MATERIAL AND METHODS}

A descriptive cross-sectional study of CTS was carried out among hairstylists in Gaborone, Botswana. A total of 184 hairstylists from randomly-selected hair salons in the city participated in the study. Per each shopping centre, half of the hair salons were randomly selected using the lot- tery method. The names of all the salons at any shopping centre were written on a paper and put into a hat, and the researcher picked randomly papers with the names of the hair salons to be selected. In each hair salon, the people who volunteered were also chosen using the same lottery method. The sample size was calculated using a single proportion formula considering a $95 \%$ confidence interval (CI) and a $5 \%$ margin of error. Since there were no previous studies conducted in Botswana, the authors utilized the prevalence studied in Turkey as $\mathrm{p}=74.3 \%$ [8]. This was calculated using the following formula:

$$
\mathrm{Z}_{1-\alpha / 2}^{2} \mathrm{P}(1-\mathrm{P}) / \mathrm{d}^{2}
$$

where

$\mathrm{Z}_{1-\alpha / 2}{ }^{2}=1.96$,

$\mathrm{P}$ - the expected proportion in the population based on a previous study [8],

$\mathrm{d}$ - the absolute error of precision (0.05).

Substituting in the formula given, $1.96^{2} \times[0.74 .3(1-$ $0.74 .3)] / 0.05^{2}=293$ participants. To participate in the study, one needed to be a full-time hairstylist and to have worked for $\geq 2$ years.

\section{Questionnaire design}

An anonymous self-administered questionnaire was used to assess the participants' demographic characteristics, CTS severity and CTS awareness, as well as the physical and psychosocial exposures of the hairstylists during the course of their work. The questionnaire was divided into 4 sections covering:

- demographic items (gender, age, educational level, marital status, and smoking and alcohol consumption) and the prevalence of CTS by asking if the participants had experienced the listed CTS symptoms;

- the participants' carpal tunnel troubles using the Boston Carpal Tunnel Syndrome Questionnaire (BCTQ); 
- psychosocial and physical work demands on hairstylists, and awkward postures, described as prolonged and repetitive wrist flexion, extension radial and ulnar deviation, abnormal patterns of wrist movements, firm grasping, a repetitive use of the hand, and the use of handheld tools that vibrate or positions that put pressure on the wrist;

- the hairstylists' level of CTS awareness.

The authors used BCTQ as a disease-specific questionnaire to elicit information on the symptoms of CTS and its functional effects. The tool is used to measure changes in the symptoms and functions, and not to diagnose CTS [9]. The questionnaire comprises a Symptom Severity Scale (SSS) and a Functional Status Scale (FSS) which are often used separately. More specifically, SSS contains 11 questions about the carpal tunnel symptoms over a typical day while FSS rates the degree of difficulty for 8 functional tasks over the same period. Each question is scored 1-5 (where 1 indicates no symptom or no functional difficulty, and 5 indicates the maximum symptoms or an inability to perform the functional task). The SSS scores were then totaled and categorized into 5 groups: no symptoms (11 pts), or mild (12-22 pts), moderate (23-33 pts), severe (34-44 pts) and very severe symptoms (45-55 pts). The FSS scores were grouped into the following categories: no difficulty (8 pts), or mild (9-16 pts), moderate (17-24 pts), severe (25-32 pts) and very severe difficulty (33-40 pts) [10].

According to Leite et al. [11], BCTQ has an excellent test-retest reliability with intraclass correlation coefficients ranging $0.8-0.9$ for both the scales. Validity has also been determined by comparing the CTS questionnaire with other upper-limb outcomes and measures of impairment such as the Disabilities of the Arm, Shoulder and Hand Questionnaire (DASH), following which some strong positive correlations were reported $(r=0.90$ and $r=0.87, p<0.001)$ [11]. The questionnaire was administered in English.

\section{Ethics}

An ethical approval was obtained from the University of Botswana Institutional Review Board and the Ministry of Health and Wellness Human Research Development Committee (Reference No. HPDME 13/18/1). A permission to conduct the research at individual salons was sought from the respective salon owners or managers. Informed consent was implied by voluntarily completing and returning the questionnaire.

\section{Data analysis}

All data were entered and analyzed using IBM, SPSS v. 25.0. An independent t-test, $\chi^{2}$ test, and regression analysis were used to analyze continuous and categorical data, respectively. Chi-square test was used to determine the basic statistical associations between CTS and individual, physical and psychosocial variables. Multivariate analysis was performed using logistic regression modeling in order to obtain the risk factors which were expressed as odds ratios (OR), with $95 \%$ CI. While CTS was used as the dependent variable, demographic items, physical and psychosocial factors acted as independent variables. The level of statistical significance was $<0.05$.

\section{RESULTS}

\section{Participants' demographics}

A total of 165 hairstylists took part in the study, with the majority being females $(\mathrm{N}=92,56 \%)$. The mean age of the respondents $(\mathrm{M} \pm \mathrm{SD})$ was $35.05 \pm 7.54$ years, with an age range of 22-63 years. Almost half of the participants $(\mathrm{N}=78)$ were senior school certificate holders. Three-fifths of the respondents $(\mathrm{N}=99)$ were never smokers while almost $16 \%(\mathrm{~N}=26)$ had quit smoking. Almost three-fifths $(\mathrm{N}=96)$ of the respondents, on the other hand, consumed alcohol, with almost one-third (31.9\%) reporting to have quit alcohol. As further shown in Table 1, the results suggest that there was a statistically significant difference between the body mass index (BMI) for males 
Table 1. Descriptive statistics of individual, lifestyle and work-related factors in the study among male and female hairstylists in Gaborone, Botswana, 2019

\begin{tabular}{|c|c|c|c|c|}
\hline \multirow{2}{*}{ Variable } & \multicolumn{3}{|c|}{$\begin{array}{l}\text { Participants } \\
(\mathrm{N}=165)\end{array}$} & \multirow{2}{*}{$\mathrm{p}$} \\
\hline & $\begin{array}{c}\text { males } \\
(\mathrm{N}=73,44.2 \%)\end{array}$ & $\begin{array}{c}\text { females } \\
(\mathrm{N}=92,55.8 \%)\end{array}$ & total & \\
\hline Age [years] $(\mathrm{M} \pm \mathrm{SD})$ & $34.5 \pm 6.4$ & $35.5 \pm 8.4$ & $35.1 \pm 7.5$ & 0.437 \\
\hline $\mathrm{BMI}(\mathrm{M} \pm \mathrm{SD})$ & $22.6 \pm 2.2$ & $24.2 \pm 3.2$ & $23.4 \pm 2.9$ & 0.005 \\
\hline Length of employment [years] $(\mathrm{M} \pm \mathrm{SD})$ & $10.9 \pm 5.8$ & $10.8 \pm 6.5$ & $10.8 \pm 6.2$ & 0.109 \\
\hline Marital status [n (\%)] & & & & 0.001 \\
\hline single & $66(90.4)$ & $60(65.2)$ & $126(76.4)$ & \\
\hline married & $7(9.6)$ & $32(34.8)$ & $39(23.6)$ & \\
\hline Educational level [n (\%)] & & & & 0.206 \\
\hline junior school certificate & $15(20.8)$ & $18(19.8)$ & $33(20.2)$ & \\
\hline senior school certificate & $30(41.7)$ & $48(52.7)$ & $78(47.9)$ & \\
\hline professional certificate & $14(19.4)$ & $18(19.8)$ & $32(19.6)$ & \\
\hline other (diploma and degree) & $13(18.1)$ & $7(7.7)$ & $20(12.3)$ & \\
\hline Smoking $[\mathrm{n}(\%)]$ & & & & 0.001 \\
\hline smokers & $26(35.6)$ & $14(15.2)$ & $40(24.2)$ & \\
\hline ex-smokers & $20(27.4)$ & $6(6.5)$ & $26(15.8)$ & \\
\hline never smoked & $27(37.0)$ & $72(78.3)$ & $99(60.0)$ & \\
\hline Alcohol consumption [n (\%)] & & & & 0.001 \\
\hline currently drinks & $55(77.5)$ & $41(44.6)$ & $96(58.9)$ & \\
\hline quit drinking & $13(18.3)$ & $39(42.4)$ & $52(31.9)$ & \\
\hline never used alcohol & $3(4.2)$ & $12(13.0)$ & $15(9.2)$ & \\
\hline Physical exercise [n (\%)] & & & & 0.001 \\
\hline none & $30(41.1)$ & $47(51.6)$ & $77(47.0)$ & \\
\hline$<5 \mathrm{~h} /$ week & $9(12.3)$ & $26(28.6)$ & $35(21.3)$ & \\
\hline$\geq 5 \mathrm{~h} /$ week & $34(46.6)$ & $18(19.8)$ & $52(36.7)$ & \\
\hline Previous injury $[\mathrm{n}(\%)]$ & $8(11)$ & $8(8.7)$ & $16(9.7)$ & 0.626 \\
\hline \multicolumn{5}{|l|}{ Working time [n (\%)] } \\
\hline$>8 \mathrm{~h} /$ day & $60(82.2)$ & $67(72.8)$ & $127(77)$ & 0.156 \\
\hline$>5$ days/week & $69(94.5)$ & $81(88.0)$ & $150(90.9)$ & 0.151 \\
\hline \multicolumn{5}{|l|}{ Customers [n (\%)] (M) } \\
\hline on a normal work day $>5$ & $61(83.6)$ & $14(15.2)$ & $75(45.5)$ & 0.001 \\
\hline when it is busy $>10$ & $70(95.9)$ & $21(22.8)$ & $91(55.2)$ & 0.001 \\
\hline Knowledge of CTS [n (\%)] & & & & 0.909 \\
\hline no & $59(80.8)$ & $75(81.5)$ & $134(71.2)$ & \\
\hline yes & $14(19.2)$ & $17(18.5)$ & $31(18.8)$ & \\
\hline
\end{tabular}


Table 1. Descriptive statistics of individual, lifestyle and work-related factors in the study among male and female hairstylists in Gaborone, Botswana, 2019 - cont.

\begin{tabular}{lcccc}
\hline \multirow{2}{*}{ Variable } & \multicolumn{3}{c}{$\begin{array}{c}\text { Participants } \\
(\mathrm{N}=165)\end{array}$} & $\mathrm{p}$ \\
\cline { 2 - 3 } & $\begin{array}{c}\text { males } \\
(\mathrm{N}=73,44.2 \%)\end{array}$ & $\begin{array}{c}\text { females } \\
(\mathrm{N}=92,55.8 \%)\end{array}$ & total & \\
\hline Aware of being at CTS risk [n (\%) & & & & 0.738 \\
no & $58(79.5)$ & $75(81.5)$ & $133(80.6)$ & \\
yes & $15(20.5)$ & $17(18.5)$ & $32(19.4)$ & \\
\hline
\end{tabular}

BMI - body mass index; CTS - carpal tunnel syndrome.

P-values were derived from either independent t-test for quantitative data or $\chi^{2}$ test for categorical data.

Bolded are statistically significant differences $(\mathrm{p}<0.05)$.

and females (22.6 \pm 2.2 vs. $24.2 \pm 3.2, p=0.005)$. A higher of proportion of single hairstylists were male $(\mathrm{N}=66,90.4 \%)$ while $34.8 \%(\mathrm{~N}=32)$ of the female hairstylists were married. The majority of the female hairstylists had never smoked $(\mathrm{N}=72,78.3 \%)$ and $6.5 \%(\mathrm{~N}=6)$ had quit smoking while $35.6 \%(\mathrm{~N}=26)$ of the male hairstylists were smokers and $27.4 \%(\mathrm{~N}=20)$ had quit smoking. On the other hand, more than three-quarters of the male respondents drank alcohol $(\mathrm{N}=55)$ compared to $54 \%(\mathrm{~N}=41)$ of the female respondents, and around $42 \%(\mathrm{~N}=39)$ of the female hairstylists had quit drinking alcohol compared to $18 \%(\mathrm{~N}=13)$ of their male counterparts.

A higher proportion of the male hairstylists $(\mathrm{N}=34$, $46.6 \%$ ) reported doing physical exercise for $>5 \mathrm{~h} /$ week, compared with only $19.8 \%(\mathrm{~N}=18)$ of their female counterparts. The majority of the hairstylists surveyed did not know about CTS nor were they at risk of the condition.

\section{Prevalence of self-reported CTS}

Overall, 73 out of 165 hairstylists (44.2\%) reported CTS symptoms. Of these, $72.6 \%(\mathrm{~N}=53)$ and $21.9 \%(16)$ reported mild and moderate severity, respectively. Minimum and severe symptoms were each reported by $2.7 \%(\mathrm{~N}=2)$ of the hairstylists, as shown in Figure 1. Most of the male hairstylists (80\%) reported mild severity compared to $72.6 \%$ of the female hairstylists. On the other hand, $25 \%$ of the females reported mod-

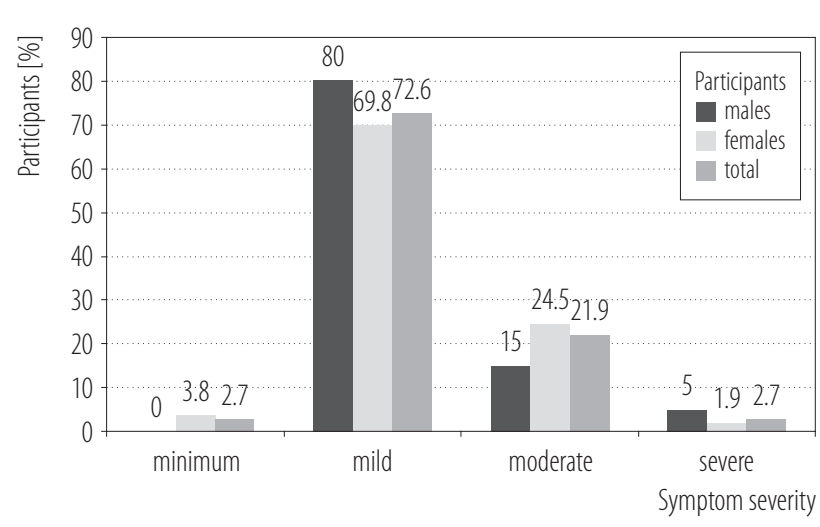

Figure 1. Severity of the carpal tunnel syndrome (CTS) symptoms among hairstylists, in the study among male and female hairstylists in Gaborone, Botswana, 2019

erate symptom severity compared to $15 \%$ of the males. In addition, $53.4 \%(\mathrm{~N}=39)$ and $41.1 \%(\mathrm{~N}=30)$ of the respondents reported no or mild difficulty when carrying out their daily activities due to experiencing CTS symptoms.

As shown in Table 2, there was an association between selfreported CTS, gender $(\mathrm{p}<0.001)$, age $(\mathrm{p}<0.001)$ and BMI ( $p<0.001)$. Alcohol consumption was also significantly associated with reporting CTS symptoms. More specifically, $13 \%$ of those who had never used alcohol reported CTS symptoms compared to $53.8 \%$ of those who had quit drinking, and to $44.8 \%$ of those who still drank ( $p<0.001$ ). There was an association between the hairstylists reporting previous wrist/hand injury and CTS symptoms ( $p<0.001)$. 
Table 2. Prevalence of self-reported carpal tunnel syndrome (CTS), in relation to individual and work-related factors, in the study among male and female hairstylists in Gaborone, Botswana, 2019

\begin{tabular}{|c|c|c|c|c|}
\hline \multirow[t]{2}{*}{ Variable } & \multicolumn{3}{|c|}{$\begin{array}{c}\text { Participants } \\
(\mathrm{N}=165) \\
{[\mathrm{n}(\%)]}\end{array}$} & \multirow[t]{2}{*}{$\mathrm{p}$} \\
\hline & $\begin{array}{l}\text { with CTS } \\
(\mathrm{N}=73)\end{array}$ & $\begin{array}{c}\text { without CTS } \\
(\mathrm{N}=92)\end{array}$ & total & \\
\hline Gender & & & & $<0.001$ \\
\hline male & $20(27.4)$ & $53(72.6)$ & $73(44.2)$ & \\
\hline female & $53(57.6)$ & $39(42.4)$ & $92(55.8)$ & \\
\hline Age & & & & $<0.001$ \\
\hline 20-30 years & $7(13.5)$ & $45(86.5)$ & $52(31.5)$ & \\
\hline $31-40$ years & $40(52.6)$ & $36(47.4)$ & $76(46.1)$ & \\
\hline$>40$ years & $26(70.3)$ & $11(29.7)$ & $37(22.4)$ & \\
\hline BMI & & & & $<0.001$ \\
\hline underweight & $3(50)$ & $3(50)$ & $6(3.6)$ & \\
\hline normal weight & $25(28.1)$ & $64(71.9)$ & $89(53.9)$ & \\
\hline overweight & $35(72.9)$ & $13(27.1)$ & $48(29.1)$ & \\
\hline Marital status & & & & $<0.001$ \\
\hline single & $42(33.3)$ & $84(66.7)$ & $126(76.4)$ & \\
\hline married & $31(79.5)$ & $8(20.5)$ & $39(23.6)$ & \\
\hline Educational level & & & & 0.842 \\
\hline junior school certificate & $15(45.5)$ & $18(54.5)$ & $33(20.0)$ & \\
\hline senior school certificate & $36(46.2)$ & $42(53.8)$ & $78(47.3)$ & \\
\hline professional certificate & $14(43.8)$ & $18(56.3)$ & $32(19.4)$ & \\
\hline other (diploma, degree) & $7(35.0)$ & $13(65.0)$ & $20(12.1)$ & \\
\hline Smoking & & & & 0.285 \\
\hline smokers & $18(45)$ & $22(55.0)$ & $40(24.2)$ & \\
\hline ex-smokers & $15(57.7)$ & $11(42.3)$ & $26(15.8)$ & \\
\hline never smoked & $40(40.4)$ & $59(59.6)$ & $99(60.0)$ & \\
\hline Alcohol consumption & & & & 0.021 \\
\hline currently drinks & $43(44.8)$ & $53(55.2)$ & $96(58.2)$ & \\
\hline quit drinking & $28(53.8)$ & $24(46.2)$ & $52(31.5)$ & \\
\hline never used alcohol & $2(13.3)$ & $13(86.7)$ & $15(9.1)$ & \\
\hline Physical exercise & & & & 0.733 \\
\hline none & $35(45.5)$ & $42(54.5)$ & $77(46.7)$ & \\
\hline$\leq 5 \mathrm{~h} /$ week & 17 (48.6) & $18(51.4)$ & $35(21.2)$ & \\
\hline$>5 \mathrm{~h} /$ week & $21(40.4)$ & $31(59.6)$ & $52(31.5)$ & \\
\hline
\end{tabular}


Table 2. Prevalence of self-reported carpal tunnel syndrome (CTS), in relation to individual and work-related factors, in the study among male and female hairstylists in Gaborone, Botswana, 2019 - cont.

\begin{tabular}{|c|c|c|c|c|}
\hline \multirow[t]{2}{*}{ Variable } & \multicolumn{3}{|c|}{$\begin{array}{c}\text { Participants } \\
(\mathrm{N}=165) \\
{[\mathrm{n}(\%)]}\end{array}$} & \multirow[t]{2}{*}{$\mathrm{p}$} \\
\hline & $\begin{array}{l}\text { with CTS } \\
(\mathrm{N}=73)\end{array}$ & $\begin{array}{c}\text { without CTS } \\
(\mathrm{N}=92)\end{array}$ & total & \\
\hline Previous injury & & & & $<0.001$ \\
\hline no & $57(38.3)$ & $92(61.7)$ & $149(90.3)$ & \\
\hline yes & $16(100)$ & $0(0.0)$ & $16(9.7)$ & \\
\hline Work experience & & & & $<0.001$ \\
\hline$\leq 10$ years & $24(25.8)$ & $49(68.1)$ & $73(44.2)$ & \\
\hline$>10$ years & $69(74.2)$ & $23(31.9)$ & $92(55.8)$ & \\
\hline \multicolumn{5}{|l|}{ Frequently performed tasks } \\
\hline braiding (singles) & $19(48.7)$ & $20(51.3)$ & $39(23.6)$ & 0.520 \\
\hline plaiting (carrot, condrow) & $42(55.3)$ & $34(44.7)$ & $76(46.1)$ & 0.008 \\
\hline washing (hair relaxing, treating) & $50(60.2)$ & $33(39.8)$ & $83(50.3)$ & $<0.001$ \\
\hline haircuts & $23(29.5)$ & $55(70.5)$ & $78(47.3)$ & $<0.001$ \\
\hline dreadlocks (twisting and crocheting) & $17(43.6)$ & $22(56.4)$ & $39(23.6)$ & 0.925 \\
\hline Awkward posture & & & & $<0.001$ \\
\hline no & $13(22.4)$ & $45(77.6)$ & $58(35.2)$ & \\
\hline yes & $60(56.1)$ & $47(43.9)$ & $107(64.8)$ & \\
\hline $\begin{array}{l}\text { Use of a great muscular effort } \\
\text { when performing a task }\end{array}$ & & & & $<0.001$ \\
\hline no & $15(23.8)$ & 48 (76.2) & $63(38.2)$ & \\
\hline yes & $57(56.4)$ & 44 (43.6) & $101(61.2)$ & \\
\hline \multicolumn{5}{|l|}{ Mostly used tools } \\
\hline hair dryer & $51(56.7)$ & $39(43.3)$ & $90(54.5)$ & $<0.001$ \\
\hline hair clipper & $23(29.5)$ & $55(70.5)$ & $78(47.3)$ & $<0.001$ \\
\hline scissors & $32(48.5)$ & $34(51.5)$ & $66(40.0)$ & 0.370 \\
\hline hair iron & $12(66.7)$ & $6(33.3)$ & 18 (10.9) & 0.042 \\
\hline Workload & & & & $<0.001$ \\
\hline light & $4(19)$ & $17(89.0)$ & $21(12.7)$ & \\
\hline moderate & 44 (38.9) & 69 (61.1) & $113(68.5)$ & \\
\hline heavy & $25(80.6)$ & $6(19.4)$ & 31 (18.8) & \\
\hline Stressful work & & & & $<0.001$ \\
\hline no & $22(28.2)$ & $56(71.8)$ & 78 (47.3) & \\
\hline sometimes & $28(54.9)$ & $23(45.1)$ & $51(30.9)$ & \\
\hline yes & $23(63.9)$ & $13(36.1)$ & $36(21.8)$ & \\
\hline
\end{tabular}

Bolded are statistically significant differences $(\mathrm{p}<0.05)$. 
There was also an association between working experience and reporting CTS symptoms ( $p<0.001)$, as shown in Table 2. The results also indicate an association between reporting CTS symptoms and the tasks performed, an awkward posture and commonly used tools. The hairstylists who reported that their work was stressful were more likely to experience CTS symptoms ( $\mathrm{p}<0.001)$.

\section{Risk factors for self-reported CTS}

As shown in Table 3, individual factors such as gender, increasing age, the length of employment and alcohol consumption were predictors of CTS symptoms. The females were 10 times more likely to report the occurrence of CTS symptoms when compared to their male counterparts (OR 9.99, 95\% CI: 3.64-27.44). The hairstylists aged 31-40 years and those aged $>40$ years were 9.84 and 14.92 times, respectively, more likely to report experiencing CTS symptoms when compared to those aged 20-30 years. Among the workrelated factors, the hairstylists who reported frequently washing hair were almost 3 times more likely to develop CTS symptoms (OR 2.88, 95\% CI: 1.41-5.85) than those who did not. An awkward posture, the use of a great muscular effort when performing a task, and heavy workload were also predictors of self-reported CTS. Stress at work was the only psychosocial risk factor that remained a statistically significant risk factor for CTS symptoms.

\section{DISCUSSION}

\section{Prevalence of self-reported CTS}

This study established a high prevalence of CTS symptoms among hairstylists in Gaborone, similar to the studies conducted in Portugal (43\%) [12], Egypt (41\%) [13], and Iran (49\%) [14]. However, compared to the studies conducted among hairstylists in the United Kingdom [15], Taiwan [16], Ethiopia [17], Nigeria [18], and Brazil [19], the prevalence rate in this study was higher. The prevalence of CTS was found to be as high as $74 \%$ in countries such as Turkey [8]. This study further established that female hairstylists had a higher CTS symptoms prevalence than their male counterparts.

Compared to other occupational groups, hairdressers have been found to be at an increased risk of hand/wrist pain. In a case-control study conducted in the United Kingdom with hairdressers and non-hairdressing controls, hairdressers were 3 times more likely to report hand/wrist pain (OR 2.8, 95\% CI: 1.1-7.6) [15]. Turkish female hairdressers were also reported to be at an increased risk of CTS as $74.3 \%$ of them reported CTS compared to $55 \%$ of the unemployed control group $(p=0.032)$ [8]. In another comparative study with office workers, Egyptian female hairdressers had a significantly higher prevalence rates of hand/wrist pain (41\% vs. $4 \%, \mathrm{p}<0.05)$ [13]. The review of previous research suggests that the prevalence of hand/wrist pain among hairdressers ranges $11-86.6 \%$ [8,13-15,18,20]. Consequently, hairdressers have been reported to have subsequently left their profession because of ill-health [4].

The relatively high prevalence of self-reported CTS among Gaborone hairstylists could be attributed to the high workload of hairstylists and the lack of regular breaks. Most hair salons in Gaborone are rent-a-chair facilities where hairstylists are expected to pay the rent for the workstation and furniture they use in the salon. The hairdresser has to work extra hours in order to be able to pay the salon rent, to earn a decent take-home salary, and to purchase hair products to serve customers. Adeumi-Gunn et al. [20] have also suggested that a high prevalence of hand/wrist pain in their study could be attributed to the long hours and the lack of ergonomically efficient workstations. It is important to identify the different risk factors that lead to CTS symptoms among hairstylists in order to understand their impacts and to come up with appropriate interventions to reduce the prevalence and severity of symptoms.

\section{Risk factors for self-reported CTS}

The current study shows that that the occurrence of CTS symptoms is multi-factorial in nature. Among the indi- 
Table 3. Risk factors of carpal tunnel syndrome (CTS) in the study among male and female hairstylists in Gaborone, Botswana, 2019

\begin{tabular}{|c|c|c|}
\hline Risk factor $^{\mathrm{a}}$ & Logistic OR (95\% CI) & $\mathrm{p}$ \\
\hline \multicolumn{3}{|l|}{ Gender } \\
\hline male & $1^{\mathrm{b}}$ & \\
\hline female & $9.99(3.64-27.44)$ & $<0.001$ \\
\hline \multicolumn{3}{|l|}{ Age } \\
\hline $20-30$ years & $1^{\mathrm{b}}$ & \\
\hline $31-40$ years & $9.84(2.74-35.36)$ & $<0.001$ \\
\hline$>40$ years & $14.92(3.03-73.56)$ & $<0.001$ \\
\hline \multicolumn{3}{|l|}{ BMI } \\
\hline underweight & $1^{\mathrm{b}}$ & \\
\hline normal weight & $0.41(0.07-2.509)$ & 0.33 \\
\hline overweight & $0.06(0.003-1.16)$ & 0.06 \\
\hline \multicolumn{3}{|l|}{ Alcohol consumption } \\
\hline never used alcohol & $1^{\mathrm{b}}$ & \\
\hline quit drinking & $7.58(1.55-37.02)$ & 0.012 \\
\hline currently drinks & $5.27(1.13-24.7)$ & 0.035 \\
\hline \multicolumn{3}{|l|}{ Work experience } \\
\hline$\leq 10$ years & $1^{\mathrm{b}}$ & \\
\hline$>10$ years & $3.73(1.39-9.95)$ & $<0.001$ \\
\hline \multicolumn{3}{|l|}{ Plaiting (carrot, condrow) } \\
\hline no & $1^{\mathrm{b}}$ & \\
\hline yes & $0.90(0.33-2.50)$ & 0.84 \\
\hline \multicolumn{3}{|l|}{ Washing (hair relaxing, treating) } \\
\hline no & $1^{\mathrm{b}}$ & \\
\hline yes & $2.88(1.41-5.85)$ & 0.004 \\
\hline \multicolumn{3}{|l|}{ Haircuts } \\
\hline no & $1^{\mathrm{b}}$ & \\
\hline yes & $0.44(0.15-1.26)$ & 0.124 \\
\hline \multicolumn{3}{|l|}{ Awkward posture when performing task } \\
\hline no & $1^{\mathrm{b}}$ & \\
\hline yes & $2.52(1.03-6.19)$ & 0.044 \\
\hline \multicolumn{3}{|c|}{ Use of a great muscular effort when performing a task } \\
\hline no & $1^{\mathrm{b}}$ & \\
\hline yes & $2.39(1.01-5.72)$ & 0.049 \\
\hline \multicolumn{3}{|l|}{ Mostly used tools } \\
\hline \multicolumn{3}{|l|}{ hair dryer } \\
\hline no & $1^{\mathrm{b}}$ & \\
\hline yes & $1.95(0.87-4.33)$ & 0.103 \\
\hline
\end{tabular}


Table 3. Risk factors of carpal tunnel syndrome (CTS) in the study among male and female hairstylists in Gaborone, Botswana, 2019 - cont.

\begin{tabular}{|c|c|c|}
\hline & Logistic OR $(95 \% \mathrm{CI})$ & $\mathrm{p}$ \\
\hline \multicolumn{3}{|c|}{$\begin{array}{l}\text { Mostly used tools - cont. } \\
\text { hair clipper }\end{array}$} \\
\hline no & $1^{\mathrm{b}}$ & \\
\hline yes & $0.68(0.29-1.62)$ & 0.39 \\
\hline \multicolumn{3}{|l|}{ scissors } \\
\hline no & $1^{\mathrm{b}}$ & \\
\hline yes & $0.69(0.32-1.48)$ & 0.34 \\
\hline \multicolumn{3}{|l|}{ hair iron } \\
\hline no & $1^{\mathrm{b}}$ & \\
\hline yes & $1.47(0.46-4.72)$ & 0.52 \\
\hline \multicolumn{3}{|l|}{ Workload } \\
\hline light & $1^{\mathrm{b}}$ & \\
\hline moderate & $2.71(0.86-8.59)$ & 0.09 \\
\hline heavy & $17.71(4.32-72.33)$ & $<0.001$ \\
\hline \multicolumn{3}{|l|}{ Stressful work } \\
\hline no & $1^{\mathrm{b}}$ & \\
\hline sometimes & $4.5(1.94-10.43)$ & $<0.001$ \\
\hline yes & $3.1(1.48-6.49)$ & 0.003 \\
\hline
\end{tabular}

${ }^{a}$ Risk factors evaluated simultaneously using logistic regression.

${ }^{\mathrm{b}}$ Reference.

Bolded are statistically significant values $(\mathrm{p}<0.05)$.

vidual factors positively associated with CTS symptoms is gender which is similar to other studies [21,22]. According to Chen et al. [22], female hairdressers are at an increased risk of CTS due to high force exertion and wrist velocity combined with prolonged exposure. In this study, the most frequently performed tasks were braiding, plaiting, washing hair, which included hair straightening, treating and weaving. Braiding and plaiting can take $>4 \mathrm{~h}$ to complete on 1 individual depending on the client's preference. Most of these activities are done by female hairstylists. According to Adewumi-Gunn et al. [20], using intricate braiding techniques, standing long periods, and working through breaks can lead to serious ergonomic problems. In general, women have smaller wrists and smaller carpal tunnel passageways. Additionally, female-specific factors such as hormonal changes and pregnancy have been found to contribute to CTS development in women [23].

The majority of hairstylists involved in this study who reported CTS symptoms were those aged $>30$ years. The hairstylists aged $31-40$ years and those aged $>40$ years were 9.84 times and 14.92 times, respectively, more likely to report experiencing CTS symptoms compared to the younger ones, suggesting that the older hairstylists were at an increased risk of developing CTS symptoms. Similar conclusions could be drawn from other studies where the increasing age was positively associated with CTS $[8,15,18,19,21]$. This may be due to some degenerative changes associated with ageing which may also be exaggerated by stress placed on the hand/ wrist area by the identified risk factors [18]. However, 
Mahdavi et al. [14] in their study did not find any significant association between age and CTS.

The length of employment also correlates with the presence of CTS symptoms. The hairstylists with $>10$ years of work experience were more likely to report CTS symptoms. This is in agreement with the results of previous studies of CTS among hairdressers conducted in Brazil [19], Turkey [8], Nigeria [18], India [21], Taiwan [16], and the United Kingdom [8]. This association could be attributed to a cumulative effect of workload on the worker's wrist through subsequent years of employment [18]. Furthermore, musculoskeletal disorders are cumulative in nature as they result from repeated exposures over a period of time [24].

The current study also shows a significant association between alcohol consumption and experiencing CTS symptoms. There appear to be no studies that have previously linked alcohol consumption with CTS, and the authors are not sure of the reasons behind this association. This will be investigated further in future studies.

Similar to previous studies [14,25], this study established an association between hair washing and CTS symptoms. In the context of this study, hair washing was taken as a process which could start with hair dying/hair relaxing, washing, drying and, thereafter, styling. Hair styling and dying [14,25], and also hair shampooing [25], have been associated with work-related upper-limb disorders among hairdressers. When performing these activities, hairstylists assume awkward postures especially when using great movement to perform a task. An awkward posture and great movements when performing a task were positively associated with an increased risk of experiencing CTS symptoms in the current study. According to Demiryurek and Gündoğdu [8], the constant flexion-extension movements in the wrist to use the scissors, hair dryers and blow dryers strain the hairdressers' arms. Moreover, the forced steadiness of the wrists in a flexed position during the use of combs while cutting and flattening hair could probably cause the gradual thickening of the flexor retinaculum, thus leading to the development of CTS in the hairdressers' arms over the years.

Heavy workload was also significantly associated with CTS symptoms, which is in agreement with previous research by the European Agency for Safety and Health at Work (EUOSHA) [24]. In brief, EU-OSHA has found that most musculoskeletal disorders are cumulative disorders resulting from repeated exposures to high or low intensity loads over a long period of time [24]. Workload strain has also been reported as a CTS risk factor in previous research [12,18,26,27]. In the current study, heavy workload could be attributed to plaiting which normally takes an average of $4 \mathrm{~h}$ depending on the style. Furthermore, hairdressing is a seasonal job, so there are those times of the months where business is low, and during the month-end and at weekends the demand usually goes up. Hairstylists are, therefore, forced to attend to as many customers as they can. This, in turn, leads to inadequate breaks between customers which reduce the recovery period. This also explains why the hairstylists who reported that their work was stressful were at an increased risk of experiencing CTS symptoms.

Working overtime [12], inadequate breaks [18] and attending to a large number of clients per day $[18,27]$ have also been associated with CTS. In their study among Swedish female hairdressers, Wahlstrom et al. [28] concluded that a hairdresser performing only customer tasks would be at risk of contracting disorders in the shoulder and neck, and that the occurrence of auxiliary non-customer tasks, including breaks, is needed to reduce the overall job exposure as well as to offer a more diverse exposure.

The study shows that the majority of hairdressers were not aware of CTS and that due to the nature of their work, they were at an increased risk of severe pain and sickness absence. To the best of the authors' knowledge, this was the first study undertaken to assess the CTS symptoms among hairdressers in Botswana. This is despite the fact that hairdressing is a common occupation in the service sector in Botswana. 
There is convincing literature that hairdressers have more musculoskeletal disorders and higher associated pain intensity levels $[15,29,30]$. Literature further reveals that hand/ wrist pain leads to a significant number of hairdressers visiting a doctor, and that shoulder and back pain contributes to sickness absences among hairdressers [13]. The high prevalence of CTS symptoms in this study, accompanied by the limited awareness of CTS, calls for efforts to improve the awareness of CTS among hairdressers in order to promote some behavioral changes as well as organizational and technological approaches [29,30]. In this study, it was also noted that the rent-a-chair facility makes every hairdresser their own employer. This poses the risk of overworking and an increased risk of developing CTS symptoms.

The results of this study clearly show that there was a significant relationship between CTS symptoms and workload. The hairdressers with a heavy workload exhibited an increased risk of experiencing CTS symptoms. The salon owners are, therefore, not available on a day-to-day basis to play an important role of the employer in preventing work-related health risks. It may be necessary to equally establish the knowledge levels on CTS among salon owners to influence both the design of the work environment and how the salon is organized. These actions, when accompanied by constant communication, will result in a lasting impact on CTS prevention in the workplace [4]. This is worrisome as hairstylists may be unnecessarily putting strain on themselves when working, being unaware that they are likely to develop CTS.

\section{CONCLUSIONS}

This study has revealed that CTS symptoms are common among hairstylists in Gaborone, Botswana, and that it is multi-factorial in nature. Individual factors such as gender, increasing age, alcohol consumption and the length of employment were identified as risk factors. Future studies should explore the reasons behind alcohol consumption and experiencing CTS symptoms. Hair washing, an awkward posture, the use of a great muscular effort when performing a task, perceived heavy workload and stressful work were also found to contribute to the development of CTS symptoms. Although the majority reported mild symptoms of CTS and its mild interference with daily activities, there is a need to raise the level of awareness of this syndrome among the study population. It is also important to assess the level of awareness among salon owners to influence improvements in workstation designs and to create workplace safety rules for all hairdressers renting such facilities. This will help to reduce the prevalence and progression of this condition as hairstylists have been reported to have left their profession due to CTS. Furthermore, future large-scale research is needed to establish the extent of CTS countrywide in order to influence policy-making as CTS is currently not listed amongst occupational health diseases in Botswana.

\section{Recommendations}

Based on the findings of this study regarding the prevalence, risk factors and level of CTS awareness, it is recommended that hairdressers and salon managers undergo occupational health and safety induction training which involves occupational hazards that hairdressers are exposed to. This should include training on CTS and factors associated with its development, and on measures that could be in place in order to prevent its development and progression. It is also recommended that salon working times be regulated and enforced to allow hairdressers enough time of recovery.

\section{Study limitations}

A number of limitations were identified in the current study. As a cross-sectional study, only associations can be established but no inferences of causality can be made. Further limitations of this study that need to be acknowledged are the possibility of recall bias and the self-reporting of CTS. It is not clear if the participants correctly remembered the presence of CTS symptoms in the past months 
which could lead to over- or underestimation. The presence of CTS symptoms depends solely on the subjective self-report of the participants and is not based on an objective and clinically verified diagnosis of a specialist.

\section{ACKNOWLEDGMENTS}

The authors would like to thank Lindiwe Lepodise for contribution to the conduction of the statistical analysis.

\section{REFERENCES}

1. Yazici J. Diseases of spinal nerves Neurology. In: Oge E, editor. Istanbul Faculty of Medicine Basic and Clinical Science text books. Istanbul: Nobel; 2004. p. 573-90.

2. Bland JD. Do nerve conduction studies predict the outcome of carpal tunnel decompression? Muscle Nerve. 2001;24(7):93540, https://doi.org/10.1002/mus.1091.

3. National Research Council and Institute of Medicine. Musculoskeletal Disorders and the Workplace: Low Back and Upper Extremities. Washington, DC: The National Academies Press; 2002.

4. Kozak A, Wirth T, Verhamme M, Nienhaus A. Musculoskeletal health, work-related risk factors and preventive measures in hairdressing: a scoping review. J Occup Med Toxicol. 2019;14(1):24, https://doi.org/10.1186/s12995-019-0244-y.

5. Kim JY, Kim JI, Son JE, Yun SK. Prevalence of carpal tunnel syndrome in meat and fish processing plants. J Occup Health. 2004;46(3):230-4, https://doi.org/10.1539/joh.46.230.

6. Armstrong T, Dale AM, Franzblau A, Evanoff BA. Risk Factors for Carpal Tunnel Syndrome and Median Neuropathy in a Working Population. J Occup Environ Med. 2008;50(12): 1355-64, https://doi.org/10.1097/JOM.0b013e3181845fb1.

7. Roquelaure Y, Ha C, Nicolas G, Pélier-Cady MC, Mariot C, Descatha A, et al. Attributable risk of carpal tunnel syndrome according to industry and occupation in a general population. Arthritis Rheum. 2008;15;59(9):1341-8, https://doi.org/ 10.1002/art.24002.

8. Demiryurek BE, Gündoğdu AA. Prevalence of carpal tunnel syndrome and its correlation with pain amongst female hairdressers. Int J Occup Med Environ Health. 2018;31(3): 333-9, https://doi.org/10.13075/ijomeh.1896.01068.

9. Jongs R. Carpal Tunnel Questionnaire. J Physiother. 2017;63(2):119, https://doi.org/10.1016/j.jphys.2017.02.001.

10. Levine DW, Simmons BP, Koris MJ, Daltroy LH, Hohl GG, Fossel AH, et al. A self-administered questionnaire for the assessment of severity of symptoms and functional status in carpal tunnel syndrome. J Bone Joint Surg Am. 1993;75(11): 1585-92, https://doi.org/10.2106/00004623-199311000-00002.

11. Leite JC, Jerosch-Herold C, Song F. A systematic review of the psychometric properties of the Boston Carpal Tunnel Questionnaire. BMC Musculoskelet Disord. 2006;(7):78, https://doi.org/10.1186\%2F1471-2474-7-78.

12. Cruz J, Dias-Teixeira M. Prevalence of skeletal muscle injuries in hairdressers in the distrist of Setubal. In: Arezes PM, Baptista JS, Barroso MP, Carneiro P, Cordeiro P, Costa N, et al., editors. Occupational Health and Hygiene III. London: Taylor \& Francis Group; 2015. p. 355-8.

13. Hassan OM, Bayomy H. Occupational Respiratory and Musculoskeletal Symptoms among Egyptian Female Hairdressers. J Community Health. 2015;40(4):670-9, https://doi. org/10.1007/s10900-014-9983-y.

14. Mahdavi S, Mahdavi MR, Safary M, Rashidi R, Dehghani T, Kosari M. Evaluation of the risk of musculoskeletal disorders using Rapid Entire Body Assessment among hairdressers in Khorramabad, Iran, in 2014. JOHE. 2013;2(3):138-45, https://doi.org/10.18869/acadpub.johe.2.3.138.

15. Bradshaw L, Harris-Roberts J, Bowen J, Rahman S, Fishwick, D. Self-reported work-related symptoms in hairdressers. Occup Med. 2011;61(5):328-34, https://doi.org/10.1093/occmed/kqr089.

16. Fang HL, Chen RCC, Fang HP, Xu Q. An ergonomic approach to an investigation into the risk factors leading to work-related musculoskeletal disorder for Taiwanese hairdressers. In: Proceedings of International Association of Societies of Design Research (IASDR). 2007 Nov 12; The Hong Kong Polytechnic University, Hong Kong; 2007.

17. Mekonnen TH. The magnitude and factors associated with work-related back and lower extremity musculoskeletal 
disorders among barbers in Gondar town, northwest Ethiopia, 2017: A cross-sectional study. Plos One. 2019;14(7):2019, https://doi.org/10.1371/journal.pone.0220035.

18. Aweto HA, Tella BA, Johnson OY. Prevalence of work-related musculoskeletal disorders among hairdressers. Int J Occup Med Env. 2015;28(3):545-55, https://doi.org/10.13075/ ijomeh.1896.00291.

19. Mussi G, Gouveia N. Prevalence of work-related musculoskeletal disorders in Brazilian hairdressers. Occup Med (Lond). 2008;58(5):367-9, https://doi.org/10.1093/occmed/kqn047.

20. Adewumi-Gunn TA, Ponce E, Flint N, Robbins W. A Preliminary Community-Based Occupational Health Survey of Black Hair Salon Workers in South Los Angeles. J Immigr Minor Health. 2018;20(1):164-70, https://doi.org/10.1007/ s10903-016-0521-0.

21. Kaushik A, Patra P. Upper extremity and neck disability in male hairdressers with concurrent changes in pinch strength: an observational study. Healthline. 2014;5(2):46-52, http:// iapsmgc.org/index_pdf/160.pdf.

22. Chen HC, Chang CM, Liu YP, Yong C. Ergonomic risk factors for the wrists of hairdressers. ApplErgon. 2010;41(1):98105, https://doi.org/10.1016/j.apergo.2009.05.001.

23. Roquelaure Y, Ha C, Pelier-Cady MC, Nicolas G, Descatha A, Leclerc A, et al. Work increases the incidence of carpal tunnel syndrome in the general population. Muscle Nerve. 2008;37(4):477-82, https://doi.org/10.1002/mus.20952.

24. Podniece Z, Heuvel S, van den Blatter B. Work-related musculoskeletal disorders: prevention report. Luxembourg: European Agency of Safety and Health at Work; 2008.
25. Mastrominico E, Breschi C, Fattori GC, Pini F, Carnevale F. [Biomechanical overcharge of the upper limbs in hairdressers: from the task analysis to the job/exposition matrix]. G Ital Med Lav Ergon. 2007;29(3):297-8. Italian.

26. Tsigonia A, Tanagra D, Linos A, Merekoulias G, Alexopoulos EC. Musculoskeletal disorders among cosmetologists. Int J Environ Res Public Health. 2009;6(12):2967-79, https://doi.org/10.3390/ijerph6122967.

27. De Smet E, Germeys F, De Smet L. Prevalence of work related upper limb disorders in hairdressers: A cross sectional study on the influence of working conditions and psychological, ergonomic and physical factors. Work. 2009;34:325-30, https://doi.org/10.3233/WOR-2009-0930.

28. Wahlstrom J, Mathiassen SE, Liv P, Hedlund P, Ahlgren C, Forsman M. Upper arm postures and movements in female hairdressers across four full working days. Ann Occup Hyg. 2010;54(5):584-94, https://doi.org/10.1093/annhyg/meq028.

29. Luttmann A, Jager M, Griefahn B, Caffier G, Liebers F, Steinberg U. Preventing musculoskeletal disorders in the workplace [Internet]. Geneva: World Health Organization; 2003 [cited 2020 May 5]. Available from: https://apps. who.int/iris/handle/10665/42651.

30. Yazdani A, Neumann WP, Imbeau D, Bigelow P, Pagell M, Wells R. Prevention of musculoskeletal disorders within management systems: A scoping review of practices, approaches, and techniques. Appl Ergon. 2015;51:255-62, https://doi.org/10.1016/j.apergo.2015.05.006.

This work is available in Open Access model and licensed under a Creative Commons Attribution-NonCommercial 3.0 Poland License - http://creativecommons.org/ licenses/by-nc/3.0/p1/deed.en. 